\title{
Heliconema monopteri n. sp. (Nematoda: Physalopteridae) from Monopterus cuchia (Hamilton) (Osteichthyes: Synbranchidae) in India, with notes on the taxonomy of Heliconema spp.
}

\author{
F. MORAVEC ${ }^{1 *}$, A. CHAUDHARY ${ }^{2}$, H. S. SINGH ${ }^{2}$ \\ ${ }^{1}$ Institute of Parasitology, Biology Centre, Czech Academy of Sciences (CAS), Branišovská 31, 37005 České Budějovice, \\ Czech Republic, "E-mail: moravec@paru.cas.cz; '2Department of Zoology, Chaudhary Charan Singh University, \\ Meerut (UP) - 250004, India
}

Article info

Received December 11, 2018

Accepted January 17, 2019

\section{Summary}

A new nematode species, Heliconema monopteri n. sp. (Physalopteridae), is described from the stomach and intestine of the freshwater fish Monopterus cuchia (Hamilton) (Synbranchidae) in Bijnor district, Uttar Pradesh, India. It is mainly characterized by the lengths of spicules (468 - 510 $\mu \mathrm{m}$ and $186-225 \mu \mathrm{m}$ ), the postequatorial vulva without elevated lips, the presence of pseudolabial lateroterminal depressions and by the number and arrangement of caudal papillae. This is the first representative of the genus reported from a synbranchiform fish. Another new congeneric species, Heliconema pisodonophidis $\mathrm{n}$. $\mathrm{sp}$. is established based on a re-examination of nematodes previously reported as $H$. Iongissimum (Ortlepp, 1922) from Pisodonophis boro (Hamilton) (Ophichthidae) in Thailand; ovoviviparity in this species is a unique feature among all physalopterids. Heliconema hamiltonii Bilqees et Khanum, 1970 is designated as a species dubia and the nematodes previously reported as $H$. longissimum from Mastacembelus armatus (Lacépède) in India are considered to belong to $H$. kherai Gupta et Duggal, 1989. A key to species of Heliconema Travassos, 1919 is provided.

Keywords: parasitic nematode; Physalopteroidea; new species; freshwater fish; Synbranchiformes; South Asia
Introduction

Recent parasitological examinations of some freshwater fishes in Bijnor district, Uttar Pradesh, India carried out in August 2018, revealed the presence of physalopterid nematodes in the digestive tract of the cuchia Monopterus cuchia (Hamilton) (Synbranchidae, Synbranchiformes). A detailed study of their morphology by both light (LM) and scanning electron microscopy (SEM) shows that they represent a new species of the genus Heliconema Travassos, 1919 , which is described below.

The cuchia (maximum length $70 \mathrm{~cm}$ ) is a tropical commercial fish that occurs in freshwater and brackish-water habitats of South Asia (Pakistan, India, Nepal, Bangladesh and Myanmar). Adults are known to hibernate in mud during cold season (Froese and Pauly, 2018).

\section{Material and Methods}

Fish were obtained from the fish market in Bijnor (fish allegedly caught in the River Ganga), Bijnor district $\left(29.3724^{\circ} \mathrm{N}, 78.1358^{\circ} \mathrm{E}\right)$, Uttar Pradesh, India in August 2018 and these were kept alive in aquaria at $24{ }^{\circ} \mathrm{C}$ until dissection. A total of two specimens of Monopterus cuchia (total body length 37 and $45 \mathrm{~cm}$ ) were examined for the presence of parasites. The nematodes obtained were washed in physiological saline and then fixed in hot 70\% ethanol. For LM, the nematodes were cleared using glycerine. Drawings

\footnotetext{
* - corresponding author
} 
were made with the aid of a Zeiss drawing attachment. Specimens used for SEM were postfixed in $1 \%$ osmium tetroxide (in phosphate buffer), dehydrated through a graded acetone series, critical-point-dried and sputter-coated with gold; they were examined using a JEOL JSM-7401F scanning electron microscope at an accelerating voltage of $4 \mathrm{kV}$ (GB low mode). All measurements are in micrometres unless otherwise indicated. For comparison, specimens of Heliconema from Pisodonophis boro (Hamilton) in Thailand, identified by Moravec et al. (2007) as $H$. Iongissimum (Ortlepp, 1923) and deposited in the Helminthological Collection of the Institute of Parasitology, CAS, České Budějovice (Cat. No. N - 862), were re-examined. The fish nomenclature adopted follows FishBase (Froese and Pauly, 2018).

\section{Ethical Approval and/or Informed Consent}

All applicable institutional, national and international guidelines for the care and use of animals were followed.

\section{Results}

Family Physalopteridae Railliet, 1893

\section{Heliconema monopteri n. sp.}

(Figs. 1, 2)

Description: Medium sized, whitish nematodes with thick, transversely striated cuticle. Cephalic end rounded. Cuticle in cephalic region inflated to form cephalic vesicle extending posteriorly to about level of deirids and anteriorly forming somewhat extended collar (Figs. 1A-C, 2C). Oral aperture dorsoventrally elongate, oval, rather large, surrounded by 2 massive, rounded lateral pseudolabia. Each pseudolabium bears 2 large submedian (dorsolateral and ventrolateral) cephalic papillae and oval lateroterminal depression filled with irregularly lobular mass; small lateral amphids situated between both cephalic papillae (Figs. 1C, 2A-C). Inner surface of each pseudolabium with elongate lateral mound bearing marked triangular terminal lateral tooth (internolateral tooth) situated immediately near inner border of cephalic depression and simple flat tooth at each dorsoventral extremity; no denticles present near terminal lateral teeth (Figs. 1C, 2A-C). Buccal cavity short. Oesophagus divided into short, narrow anterior muscular portion and much longer, wide glandular portion. Nerve ring encircles muscular oesophagus approximately at its middle or somewhat posterior to it. Small simple deirids situated at about level of nerve ring (Fig. 1B). Excretory pore slightly anterior to anterior end of glandular oesophagus (Fig. 1A). Tail of both sexes with rounded tip.

Male (3 specimens; measurements of holotype in parentheses): Length of body $23.39-27.35$ (23.39) mm, maximum width 340 - 394 (340). Pseudolabia 24 - 27 (24) long. Cephalic vesicle 286 - 299 (286) long and 258 - 272 (272) wide. Buccal cavity 24 - 27 (27) long. Entire oesophagus $3.48-3.55$ (3.48) mm long, repre- senting $11-15(15) \%$ of body length; muscular oesophagus 449 - 490 (490) long and 82 - 95 (82) wide; glandular oesophagus $2.99-3.10(3.10) \mathrm{mm}$ long and $163-177$ (163) wide; length ratio of two parts of oesophagus 1:6.1 -6.9 (1:6.1). Nerve ring, deirids and excretory pore 313 - 354 (326), $299-313$ (313) and $420-$ 530 (420) from anterior extremity, respectively. Caudal end spirally coiled, provided with lateral alae supported by 4 pairs of subventral pedunculate preanal papillae arranged in couples, and 5 single pairs of subventral postanal papillae, which are rather large and pedunculate; an additional pair of small postanal sessile papillae situated ventrally slightly posterior to level of last subventral postanal pair (Figs. 1E,G, 2E). Pair of minute phasmids present posterior to ventral pair of posteriormost postanal papillae (Fig. 1E,G). Ventral surface between posteriormost ventral postanal papillae and phasmids elevated to form distinct small protuberance. Cloacal lips somewhat elevated (Fig. 2E). Ventral precloacal surface with about 12 longitudinal tesselated ridges (area rugosa) (Figs. $1 \mathrm{E}, 2 \mathrm{D}, \mathrm{E})$. Spicules unequal and dissimilar; left spicule $465-510$ (468) long, with sharply pointed tip; right spicule broader, boatshaped, 186 - 225 (186) long, tapered towards distal tip. Length ratio of spicules 1:2.07 - 2.62 (1:2.52). Length of tail $340-367$ (340).

Female ( 7 ovigerous specimens; measurements of allotype in parentheses): Length of body 29.29 - 34.07 (34.07) mm, maximum width 517 - 571 (571). Pseudolabia 27 - 41 (41) long. Cephalic vesicle 272 - 340 (272) long and 258 - 326 (272) wide. Buccal cavity 27 - 36 (36) long, 27 - 36 (36) wide. Entire oesophagus $3.80-4.62$ (4.58) mm long, representing $11-17$ (13)\% of body length; muscular oesophagus 490 - 585 (571) long and 95 (95) wide; glandular oesophagus $3.31-4.04$ (4.01) mm long and 150 190 (190) wide; length ratio of two parts of oesophagus 1:1.6 - 7.0 (1:7.0). Nerve ring, deirids and excretory pore $313-381$ (340), $299-367$ (354) and 510 - 544 (535) from anterior extremity, respectively. Vulva postequatorial, situated $16.32-20.03$ (20.03) $\mathrm{mm}$ from anterior end of body, at $54-66(59) \%$ of body length. Vulval lips not elevated. Vagina narrow, muscular, directed posteriorly from vulva. Uteri containing numerous oval, thick-shelled, embryonated (larvated) eggs (Fig. 1F); eggs $39-45 \times 27-30$ (42 $-45 \times 27-30)$, with wall $4-5(4-5)$ thick. Tail short, $177-190$ (190), with rounded tip; pair of small lateral phasmids situated near tail tip (Fig. 1D).

\section{Taxonomic summary}

Type host: Cuchia, Monopterus cuchia (Hamilton) (Synbranchidae, Synbranchiformes).

Site of infection: Stomach and intestine.

Type locality: Fish market in Bijnor (fish allegedly caught in the River Ganga), Bijnor district $\left(29.3724^{\circ} \mathrm{N}, 78.1358^{\circ} \mathrm{E}\right)$, Uttar Pradesh, India (collected in August 2018).

Prevalence and intensity: 2 fish infected/2 fish examined; 30 and 40 nematode specimens.

Type specimens: Helminthological Collection of the Institute of 

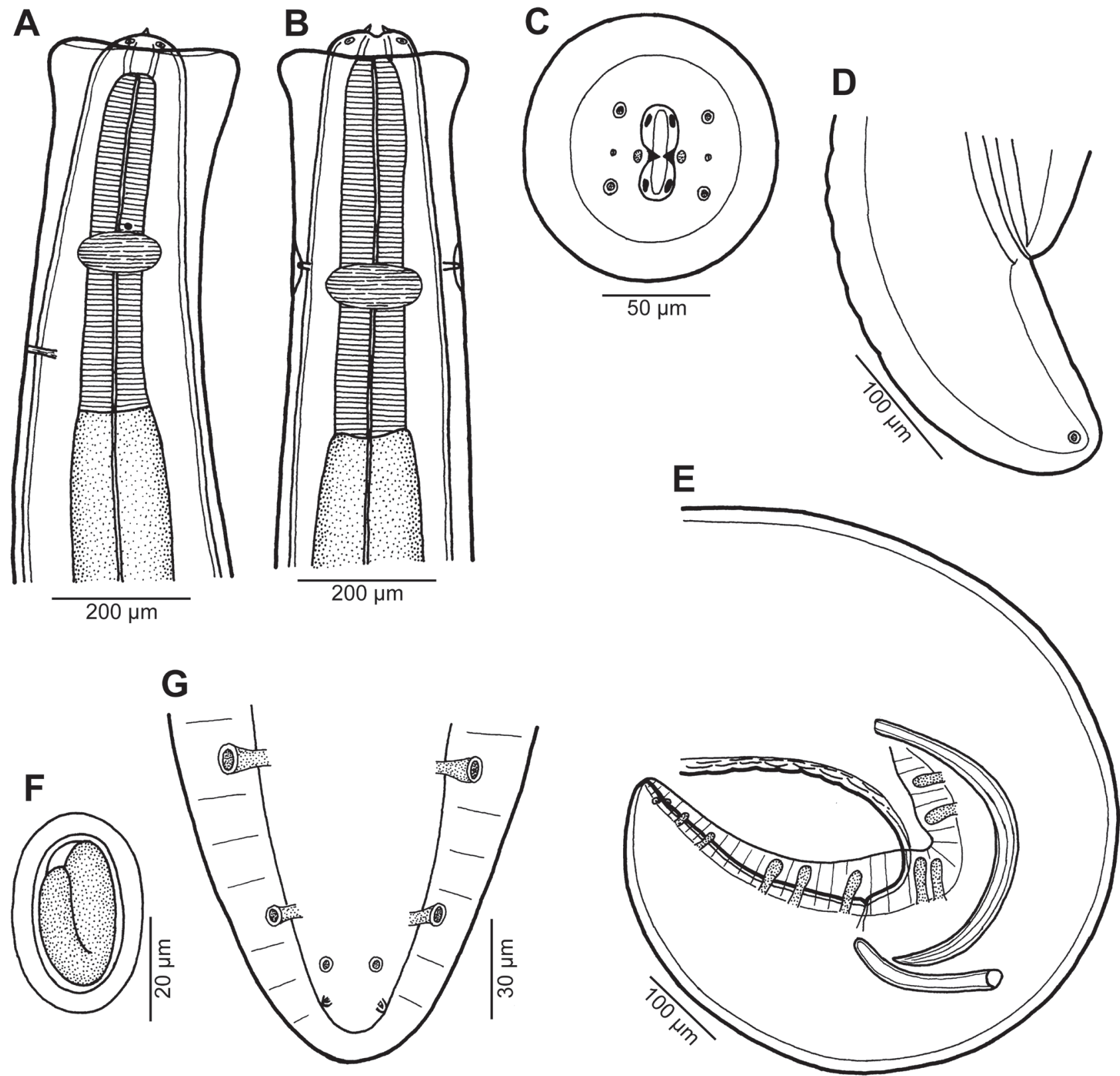

Fig. 1. Heliconema monopteri n. sp. A,B - anterior end, lateral and dorsoventral views, respectively; C - cephalic end, apical view; D - tail of female, lateral view; $\mathrm{E}$ - posterior end of male, lateral view; $\mathrm{F}$ - egg; $\mathrm{G}$ - tail tip of male, ventral view

Parasitology, Biology Centre of the Czech Academy of Sciences, České Budějovice, Czech Republic, Cat. No. N - 1186.

Etymology: The specific name of this nematode relates to the genitive form of the generic name of the host.

\section{Discussion}

The following ten recognisable species of Heliconema were reported by Li et al. (2013): H. baylisi Ogden, 1969, H. brevispiculum Baylis, 1934, H. brooksi Crites et Overstreet, 1991, H. hainanense
Li, Liu, Liu et Zhang, 2013, H. heliconema Travassos, 1919, H. kherai Gupta et Duggal, 1989, H. longissimum, H. psammobatidus Threlfall et Carvajal, 1984, H. savala Akram, 1996 and H. serpens Fusco et Palmieri, 1980. However, as mentioned by Moravec and Nagasawa (2018), later this list was extended for an additional two congeneric species, $H$. africanum (Linstow, 1899) and $H$. ahiri Karve, 1941, parasites of freshwater eels (Anguilla spp.) in South Africa and India, respectively (Linstow, 1899; Karve, 1941; Moravec et al., 2013a,b).

The present taxonomy of Heliconema spp. is rather problemat- 

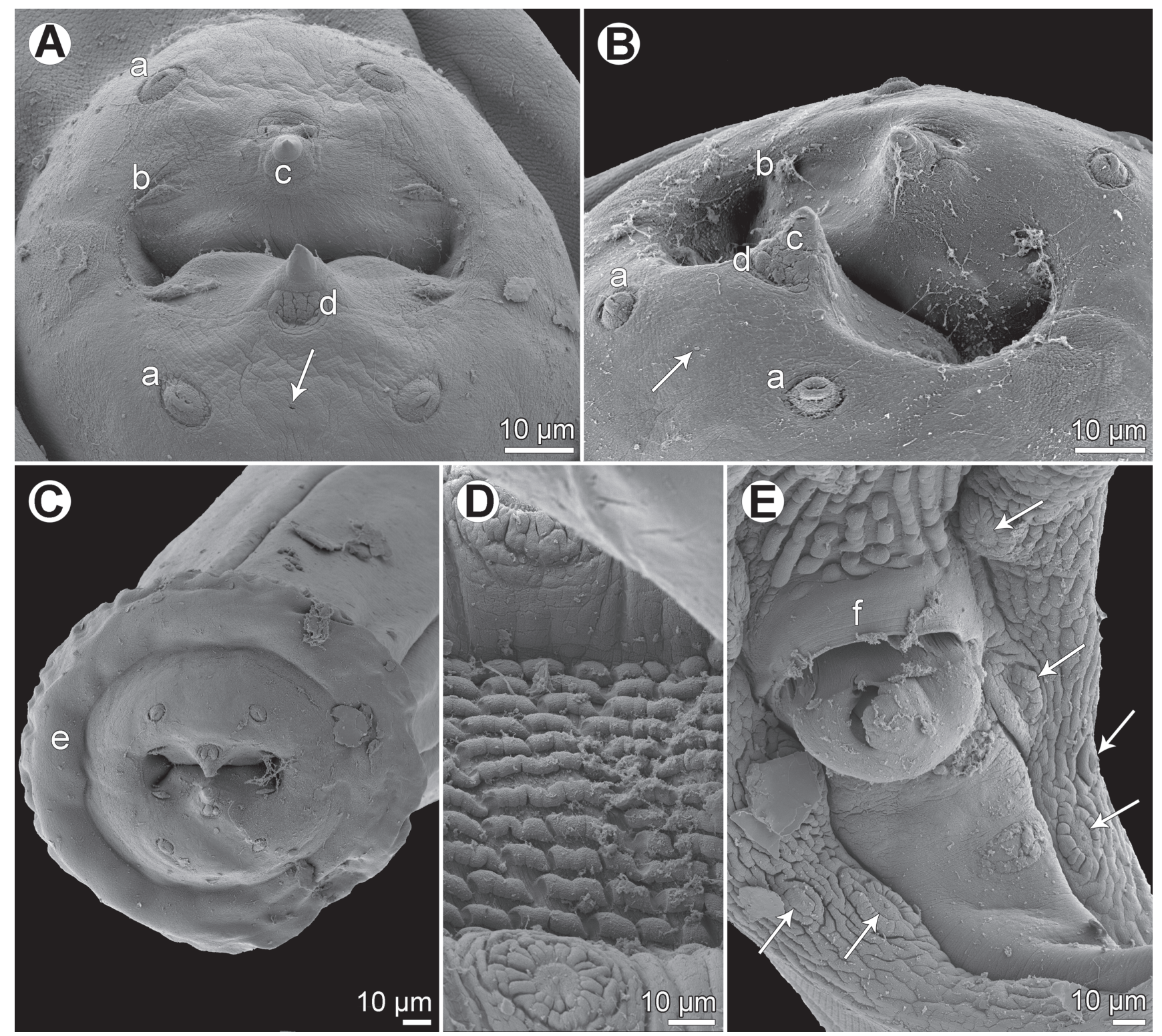

Fig. 2. Heliconema monopteri n. sp., scanning electron micrographs. A,B - cephalic end, two different subapical views (arrows indicate amphids); C - cephalic end, apical view; D - detail of ventral precloacal cuticular ridges (area rugosa), ventral view; $\mathrm{E}$ - region of cloacal aperture, ventral view (arrows indicate caudal papillae).

Abbreviations: $\mathrm{a}$ - cephalic papilla; $\mathrm{b}$ - submedian tooth; $\mathrm{c}$ - lateral tooth; $\mathrm{d}$ - lateroapical pseudolabial depression; $\mathrm{e}$ - cephalic hood; $\mathrm{f}$ - cloacal aperture

ic, because the descriptions of older species are solely based on LM observations, whereas some important morphological features, such as the cephalic structures or the exact number and distribution of caudal papillae, require the use of SEM. The situation in Heliconema is further complicated by the fact that many congeneric species have similar measurements of the body and of spicules, but they can be discriminated by features difficult or impossible to observe by LM. Apparently, this often led to wrong species identifications.

Such an example is the species $\mathrm{H}$. longissimum, originally inadequatly described as Physaloptera longissima by Ortlepp (1922) from snakes in Australia. Later it was redescribed from poorly preserved paratype specimens by Ogden (1969), who had also identified the nematodes at his disposal from Mastacembelus armatus (Lacépède) in India and those from Anguilla mossambica (Peters) in South Africa as $H$. longissimum; he also considered $H$. anguillae to be conspecific with $H$. longissimum. Subsequently, De et al. (1978) and De (1988) designated Paraleptus komiyai Sood, 1970 and Notopteroides alatae Majumdar, 1965, both parasites of $M$. armatus in India, as junior synonyms of $H$. longissimum and Moravec et al. (2007) synonymized $H$. ahiri, described from Anguilla bengalensis (Gray) in India, with this species. 
However, the subsequent study of Moravec et al. (2013b) showed that the records of $H$. Iongissimum from Anguilla mossambica reported by Ogden (1969) and Taraschewski et al. (2005) in South Africa concerned in fact $H$. africanum and that the insufficiently described $H$. longissimum might be its junior synonym. Until $H$. longissimum is redescribed in detail (including the use of SEM) based on a newly collected topotypic material and the validity of this species is confirmed, this name should only be used for the type specimens originally studied by Ortlepp (1922). Chabaud and Campana-Rouget (1956) suggested that the host (unidentified Australian snakes) of Ortlepp's type material of the species is doubtful, but, according to Moravec et al. (2013b), apparently the snakes served only as postcyclic hosts for this parasite, which acquired the infection by feeding on its true definitive hosts (fish); some species of sea snakes are known to be specialised to feed on eels. Based on newly collected materials, $H$. ahiri and $H$. anguillae were resurrected by Moravec et al. (2013a) and Katahira and Nagasawa (2015), respectively. Accordingly, the nematodes reported as $\mathrm{H}$. Iongissimum from Anguilla japonica Temminck et Schlegel in China by Li (1934) and others (see Li et al., 2013) belonged to $H$. anguillae.

Ogden (1969), De et al. (1978) and De (1988) reported H. longissimum from Mastacembelus armatus in India; De et al. (1978) and De (1988) considered Paraleptus komiyai and Notopteroides alatae, respectively, parasites of the same host species in the same region, to be synonyms of $H$. longissimum (see above). Later, Gupta and Duggal (1989) described H. kherai Gupta et Duggal, 1989 from M. armatus in India. Because of the morphological similarity of all these Indian forms, occurring in the same host species (M. armatus) that, in contrast to hosts of other Heliconema spp., belongs to the fish family Mastacembelidae, we consider them to represent one and the same species, $H$. kherai. Unfortunately, the original description of $H$. kherai is inadequate, but conspecific nematodes (as $\mathrm{H}$. longissimum) were relatively well described by other above-mentioned authors. The species has not yet been examined by SEM.

Moravec et al. (2007) described Heliconema specimens from the rice-paddy eel Pisodonophis boro (Ophichthidae) in Thailand and identified them as $\mathrm{H}$. longissimum. However, due to an insufficiently known morphology of $H$. longissimum, the validity of this species is uncertain (see above). Moravec et al. (2007) reported markedly large eggs (as compared with other Heliconema spp.) in the Thai specimens from $P$. boro, which was questioned by Katahira and Nagasawa (2015). However, the recent re-examination of these specimens deposited in the Helminthological Collection of the Institute of Parasitology, Czech Academy of Sciences surprisingly revealed that their uteri were largely filled with very numerous free first-stage larvae and small, non-shelled developing eggs, whereas typical embryonated, shelled eggs were quite rare. The presence of free larvae instead of shelled eggs is a unique feature among all hitherto known representatives of Heliconema as well as all physalopterid nematodes, in which only shelled eggs have been described. Considering also the type of the host (a representative of the Ophichthidae), we propose to establish a new species for these Thai specimens from $P$. boro, based on the description provided by Moravec et al. (2007); we propose the name $\mathbf{H}$. pisonodophidis $\mathrm{n}$. $\mathbf{s p}$. for this species (syntypes deposited in the Helminthological Collection, Institute of Parasitology CAS, České Budějovice, Czech Republic; Cat. No. N - 862). The distinction of H. pisodonophidis from other congeners is apparent from the key at the end of Discussion.

By the general morphology, the new species $H$. monopteri $\mathrm{n}$. $\mathrm{sp}$. is most similar to $H$. africanum, $H$. anguillae and $H$. pisodonophidis n. sp., differing from them mainly in having a shorter left spicule. Differences from all species of Heliconema are apparent from the key at the end of Discussion.

To date, six nominal species of Heliconema have been reported from South Asia (Bangladesh, India and Pakistan) (see also Sood, 2017): H. ahiri from Anguilla bicolor McClelland and A. bengalensis in India (Karve, 1941; Moravec et al., 2013a), H. brevispiculum from Channa marulius (Hamilton) in Bangladesh (Khan and Yaseen, 1969), H. hamiltonii Bilqees et Khanum, 1970 from Sicamugil hamiltonii (Day) in Pakistan (Bilqees and Khanum, 1970), H. heliconema from Muraenesox cinereus (Forsskål) in India and Pakistan (Khan and Begum, 1971; Gupta and Garg, 1976), H. kherai from Mastacembelus armatus in India (De et al., 1978; De, 1988; Gupta and Duggal, 1989) and H. savala from Lepturacanthus savala (Cuvier) in Pakistan (Akram, 1996); nematodes of the seventh species, $H$. longissimum, reported from India, are now considered to belong to $H$. kherai (see above).

However, except for $H$. ahiri and $H$. kherai, the congeneric nematodes from South Asia were poorly described and, judging from their unusual hosts, their species or generic identification seems to be doubtful. In particular this concerns females allegedly of $H$. brevispiculum reported from a freshwater fish (C. marulius) or the female nematodes described as a new species $H$. hamiltonii; the latter species was evidently based on anisakid larvae (!), as visible from illustrations, and it should be designated a species dubia. Consequently, $H$. monopteri $\mathrm{n}$. sp. represents an additional species of Heliconema in South Asia with well-known morphology and the second species in this region studied by SEM.

\section{Conflict of Interest}

The authors declare that they have no conflict of interest.

\section{Acknowledgements}

We thank the head of the Department of Zoology, Chaudhary Charan Singh University, Meerut, Uttar Pradesh, India, for providing laboratory facilities. Thanks are also due to the Laboratory of Electron Microscopy, Institute of Parasitology, Biology Centre CAS, institution supported by the MEYS CR (LM2015062 Czech-Biolmaging) for their support with obtaining scientific data presented in this 


\section{Key to species of Heliconema:}

1 Left spicule more than $2 \mathrm{~mm}$ long 2

- Left spicule less than $1 \mathrm{~mm}$ long

2 Adanal papillae absent; left spicule 2.09 - 3.50 mm long. Parasitic in Ophichthidae (Ophichthus); Gulf of Mexico H. brooksi

- Adanal papillae 1 - 2 pairs; left spicule equal or longer than $3.5 \mathrm{~mm}$ 3

3 Three pairs preanal papillae, 2 pairs adanal papillae; left spicule $4 \mathrm{~mm}$ long, right spicule $270 \mu \mathrm{m}$; vulva at approximately first third of body. Parasitic in Trichiuridae (Lepturacanthus); off Pakistan H. savala - Four pairs preanal papillae, 1 pair adanal papillae; left spicule $3.5-7.3 \mathrm{~mm}$, right spicule 300 - $350 \mu \mathrm{m}$; vulva at approximately second quarter of body. Parasitic in Muraenidae (Echidna) and Muraenesocidae (Muraenesox); Atlantic and Indian Oceans (off Trinidad, Senegal and Pakistan) H. heliconema

4 Pair of ventral postanal papillae just posterior to cloacal aperture present; pseudolabial lateroterminal depression present

- Pair of ventral postanal papillae just posterior to cloacal aperture absent; pseudolabial lateroterminal depression present or absent

5 Postanal papillae of fifth subventral pair pedunculate; vulva preequatorial; size of eggs $39-51 \times 20-$ $30 \mu \mathrm{m}$; length of left and right spicule $538-820 \mu \mathrm{m}$ and $200-306 \mu \mathrm{m}$, respectively. Parasitic in Anguillidae (Anguilla); East Asia (Japan, China) H. anguillae - Postanal papillae of fifth subventral pair sessile; vulva preequatorial to somewhat postequatorial; eggs 75 $81 \times 42-48 \mu \mathrm{m}$, but uterus mostly filled with free larvae; length of left and right spicule 520-734 $\mu \mathrm{m}$ and 232 $-286 \mu \mathrm{m}$, respectively. Parasitic in Ophichthidae (Pisodonophis); South-East Asia (Thailand) .... H. pisodonophidis n. sp.

6 Vulva distinctly postequatorial; pseudolabial lateroterminal depression present; dorsoventral flat teeth on each pseudolabium without nearby denticles; length of left and right spicule $468-510 \mu \mathrm{m}$ and $186-225 \mu \mathrm{m}$, respectively. Parasitic in Synbranchidae (Monopterus); South Asia (India) ....................... H. monopteri n. sp. - Vulva equatorial, exceptionally may be slightly postequatorial; pseudolabial lateroterminal depression present, absent or not reported; dorsoventral flat teeth on each pseudolabium with or without nearby denticles

7 Dorsoventral flat teeth on each pseudolabium with nearby denticles; pseudolabial lateroterminal depressions present; length of left and right spicule $408-770 \mu \mathrm{m}$ and $168-270 \mu \mathrm{m}$, respectively. Parasitic in Anguillidae (Anguilla); South Asia (India) H. ahiri

- Dorsoventral flat teeth on each pseudolabium without nearby denticles 8

8 Pseudolabial lateroterminal depressions present; vulva preequatorial; length of left and right spicule 650 $857 \mu \mathrm{m}$ and $290-400 \mu \mathrm{m}$, respectively. Parasitic in Anguillidae (Anguilla); South Africa

H. africanum

- Pseudolabial lateroterminal depressions absent or not reported; vulva equatorial or postequatorial. Parasitic in other host families

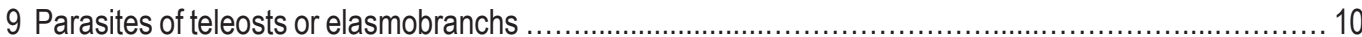

- Parasites reported from snakes 14

10 Pseudolabial lateroterminal depressions absent; vulva preequatorial; length of left and right spicule 420 $-630 \mu \mathrm{m}$ and $190-300 \mu \mathrm{m}$, respectively. Parasitic in Congridae (Uroconger) and Muraenidae (Congresox, Muraenesox); South China Sea. H. hainanense

- Pseudolabial lateroterminal depressions not reported 11 
11 Parasites of Anguilliformes or Synbranchiformes

- Parasites of Rajiformes: Vulva equatorial, with elevated anterior lip; length of left and right spicule 558 $621 \mu \mathrm{m}$ and $131-151 \mu \mathrm{m}$, respectively. Parasitic in Arhynchobatidae (Sympterigia); off Chile

H. psammobatidus

12 Parasites of Synbranchiformes: Vulva equatorial to slightly postequatorial, with non- elevated anterior lip; length of left and right spicule $420-630 \mu \mathrm{m}$ and $190-300 \mu \mathrm{m}$, respectively. Parasitic in Mastacembelidae (Mastacembelus); South Asia (India) ...... H. kherai

- Parasites of Anguilliformes ..... 13

13 Length of left and right spicule $380-440 \mu \mathrm{m}$ and $280-380 \mu \mathrm{m}$, respectively. Parasitic in Muraenidae (Echidna); Indian Ocean ..... H. baylisi - Length of left and right spicule $500-520 \mu \mathrm{m}$ and 230 - $250 \mu \mathrm{m}$, respectively; vulva equatorial with elevated anterior lip. Parasitic in Muraenesocidae (Muraenesox); off Australia H. brevispiculum

14 Vulva preequatorial; length of left and right spicule $516 \mu \mathrm{m}$ and $228-300 \mu \mathrm{m}$, respectively; size of eggs $59 \times 32 \mu \mathrm{m}$. Reported from unidentified snakes; Australia ...... H. longissimum - Vulva situated in about mid-length of body, anterior vulval lip non-elevated; length of left and right spicule $404-525 \mu \mathrm{m}$ and $247-314 \mu \mathrm{m}$, respectively; size of eggs $49-54 \times 27-31 \mu \mathrm{m}$. Parasitic in Homalopsidae (Cerberus); Malaysia H. serpens

paper, and to Blanka Škoríková of the same Institute for help with illustrations. This study was partly supported by the institutional support of the Institute of Parasitology, BC AS CR, 585110/9500).

\section{References}

Akram M.C. (1996): Heliconema savala n. sp. (Nematoda: Physalopteridae) from marine fish Lepturacanthus savala (Cuvier) (Trichuridae) and Psettodes erumei (Schneider) new host (Pisces: Psettotidae) of physalopterid nematode, Bulbocephalus inglisi Rasheed, 1966 in Pakistan. Pakistan J. Mar. Sci., 5: 132 - 143

Bilqees F.M., Khanum Z. (1970): Marine fish nematodes of West Pakistan II. A new species of the genus Heliconema from fishes of Pasni. Pakistan J. Zool., 2: $211-213$

Chabaud A.G., Campana-Rouget Y. (1956): Le genre Ortleppina Schulz, 1927, parasite d'Apodes, et non de Serpents, est synonyme de genre Heliconema Travassos, 1919. Ann. Parasitol. Hum. Comp., 31: $308-309$

DE N.C. (1988): Remarks on the validity of the species Notopteroides alatae Majumdar, 1965. Folia Parasitol., 35: 281 - 284

De N.C., Ghosh M., Majumdar G. (1978): Records of some little known nematodes from Indian fishes. Folia Parasitol., 25: 317 322

Froese R., Pauly D. (Eds) (2018): FishBase. World Wide Web electronic publication. http://www.fishbase.org, version 12/2018

GuPtA N.K., DugGaL C.L. (1989): On a new species of the genus Heliconema (Nematoda: Physalopteridae) from a freshwater fish with a key to the species of the genus. Res. Bull. (Sci.) Punjab Univ., 40: $73-75$

GUPTA N.K., GARG V.K. (1976): Observations on three already known spiruroid nematodes from marine food fishes of South In- dia. Indian J. Helminthol., 28: 17 - 28

KaRVE J.N. (1941): Some parasitic nematodes of fishes. I. J. Univ. Bombay, New Ser., 10B: 9 - 42

Katahira H., Nagasawa K. (2015): Heliconema anguillae Yamaguti, 1935, a physalopterid nematode found in Japanese eels: taxonomic resurrection with a note on the third-stage larva from intertidal crabs in western Japan. Folia Parasitol., 62: 028. DOI: 10.14411/fp.2015.028

Khan D., Begum A. (1971): Helminth parasites of fishes from West Pakistan I. Nematodes. Bull. Dept. Zool., Univ. Punjab (New Ser.), 5: $1-22$

Khan D., Yaseen T. (1969): Helminth parasites of fishes from East Pakistan I. Nematodes. Bull. Dept. Zool., Univ. Punjab (New Ser.), 4: $1-33$

LI H.C. (1934): Report on a collection of parasitic nematodes, mainly from North China. Part II. Spiruroidea. Trans. Am. Microsc. Soc., 53: $174-195$

LI L., LIU Y.-Y., LIU B.-C., ZHANG L.-P. (2013): Morphological and molecular characterization of Heliconema hainanensis sp. nov. (Spirurina: Physalopteridae) from congers in the South China Sea, with a key to the species of Heliconema. Mem. Inst. Oswaldo Cruz, 108: 41 - 47. DOI: 10.1590/s0074-02762013000100007

LINSTOW, O., Von (1899): Nematoden aus der Berliner Zoologischen Sammlung. Mitt. Zool. Sam. Mus. Naturk. Berlin, 1: 3-28, 6 Plts Moravec F., Nagasawa K. (2018): Rhabdochona angusticaudata sp. n. (Nematoda: Rhabdochonidae) from the Japanese eel $A n-$ guilla japonica, and new records of some other nematodes from inland fishes in Japan. Folia Parasitol., 65: 016. DOI: 10.14411/ fp. 2018.015

Moravec F., Sheeba S., Kumar A.B. (2013a): Observations on nematodes from the Indonesian shortfin eel Anguilla bicolor bicolor 
McClelland in India, including a revalidation of Heliconema ahiri Karve, 1941 (Physalopteridae). Acta Parasitol., 58: 496 - 503. DOI: 10.2478/s11686-013-0168-0

Moravec F., Taraschewski H., Anantaphruti M.T., Maipanich W., LAOPRASERT T. (2007): Heliconema longissimum (Ortlepp, 1923) (Nematoda: Physalopteridae) from Pisodonophis boro (Teleostei: Ophichthidae) in Thailand, with remarks on the taxonomy of the Proleptinae Schulz, 1927. Syst. Parasitol., 66: 73 - 80. DOI: 10.1007/s11230-006-9066-2

Moravec F., TaRaschewski H., Weyl O.L.F. (2013b): Redescription of Heliconema africanum (Linstow, 1899) n. comb. (Nematoda: Physalopteridae), a nematode parasite of freshwater eels ( $A n-$ guilla spp.) in South Africa. Syst. Parasitol., 85: 263 - 269. DOI: 10.1007/s11230-013-9421-z

Ogden C.G. (1969): A revision of the genus Heliconema Travassos, 1919, Physalopteridae (Nematoda). J. Nat. Hist., 3: 423 - 431 ORtLepp R.J. (1922): The nematode genus Physaloptera Rud. Proc. Zool. Soc. Lond., 1922: 999 - 1107

Sood M.L. (2017): Fish nematodes from South Asia. Second edition. Kalyani Publishers, Ludhiana, 1039 pp

Taraschewski H., Boomker J., Knopf K., Moravec F. (2005): Anguillicola papernai (Nematoda: Anguillicolidae) and other helminths parasitizing the African longfin eel Anguilla mossambica. Dis. Aquat. Org., 63: 185 - 195 